\title{
Heat wave and cold spell changes in Iberia for a future climate scenario
}

\author{
Susana Cardoso Pereira, ${ }^{\mathrm{a} *}$ (10 Martinho Marta-Almeida, ${ }^{\mathrm{b}}$ Ana Cristina Carvalho ${ }^{\mathrm{c}}$ and Alfredo \\ Rocha $^{\mathrm{a}}$ \\ ${ }^{a}$ CESAM-Department of Physics, University of Aveiro, Portugal \\ ${ }^{\mathrm{b}}$ Instituto Español de Oceanografia, Centro Oceanográfico A Coruña, Spain \\ c SMHI/Swedish Meteorological and Hydrological Institute, Research Department, Unit of Air Quality Research, Norrköping, Sweden
}

\begin{abstract}
This study investigates the impacts of climate change scenario on summer heat waves' (HWs) and winter cold spells' (CSs) characteristics for 12 locations over the Iberian Peninsula (IP). These characteristics are duration, recovery factor and intensity. Two future time slices of the chosen scenario are studied, namely, the periods 2046-2065 and 2081-2100 which are compared with a reference climate for the recent-past (1986-2005). The RCP8.5 greenhouse gas emission scenario is considered. The minimum and maximum daily temperature were obtained for these periods through regional model simulations using the Weather and Research Forecast (WRF) model forced with the MPI-ESM-LR model. The model was validated against EOBS and SPAIN02 datasets. The model shows 90th/10th percentile temperature (i.e. thresholds to identify HW/CS) biases. Therefore, HW/CS numbers and properties were evaluated using the model's respective thresholds. HW/CS numbers and characteristics were also compared between the model and EOBS derived data. Probability density functions (PDFs) of the duration, recovery factor and intensity show significant changes in the mean and variance for the summer HWs. Differences, between future and recent-past climate in the extremes are evaluated by the 95th percentile which show an increase in the duration and intensity of the HWs for the future time slices. Very few CSs were detectable in the mid-term future (2046-2065) and none in the long-term future (2080-2100), except for Barcelona. For most locations, the CS for the future are of smaller duration and intensity. The PDF of the recovery factor suggests smaller absolute differences between the minimum and maximum temperature during winter which is also confirmed by the percentile analysis. The increase in the duration and intensity of HWs is greater in the long-term future than in the mid-term future, pointing for a warmer IP with more and longer HWs towards the end of the XXI century.
\end{abstract}

KEY WORDS climate change; heat waves; cold spells; Iberian Peninsula; regional climate modelling; WRF model

Received 14 September 2016; Revised 19 April 2017; Accepted 5 May 2017

\section{Introduction}

The ecological, health and economic impacts of extreme hot/cold weather on present and in a changing climate have been established by several authors, especially after the 2003 heat wave (HW) effects on mortality over Western and Central Europe (Hansen et al., 2008; Barata et al., 2011; Ciscar et al., 2014). In the Iberian Peninsula (IP) the $2003 \mathrm{HW}$ was responsible for an excess of $3.5 \%$ mortality in Portugal and of $8 \%$ in Spain (Nogueira et al., 2005; Simón et al., 2005). The 2003 summer HW that hit intensively the Western and Central Europe, the Eastern European $2010 \mathrm{HW}$ and the extreme cold temperatures cold spells (CSs) during the 2009/2010 winter prompted an investigation of temperature extreme events over Europe.

During recent years the evidence of more frequent and severe extreme weather events, regarding their impacts, has been documented by several authors and institutions,

\footnotetext{
* Correspondence to: S. C. Pereira, CICFANO Building, Departmen of Physics, University of Aveiro, Campus Universitário de Santiago, 3810-193 Aveiro, Portugal. E-mail: susana.cardoso@ua.pt
}

(e.g. Della-Marta et al., 2007; WMO, 2011; Lubchenco and Karl, 2012; Peterson et al., 2012; Zuo et al., 2015). In a changing climate scenario it is almost certain the occurrence of increases in frequency and magnitude of daily temperature extremes and decreases in frequency and magnitude of daily minimum temperature extremes (Peterson et al., 2012). These changes may happen already this century (Cutter et al., 2012). So, it is expectable that extreme weather phenomena related to air temperature, like HWs and CSs, are likely to change towards higher maximum and minimum temperatures and more hot days and warm nights (WMO, 2011). Recent findings, for Central Europe point for a recent increase in frequency, duration and intensity of the summer HWs (Tomczyk and Bednorz, 2016) and for Europe it is expected that 'the probability of a summer experiencing mega-HW will increase by a factor of 5 to 10 within the next 40 years' (Barriopedro et al., 2011).

As pointed out by Barnett et al. (2012), the HW characteristics on health impacts are well established, whereas those of CS are still to be proved. This fact may explain why HWs have been investigated extensively in the last 
(a)

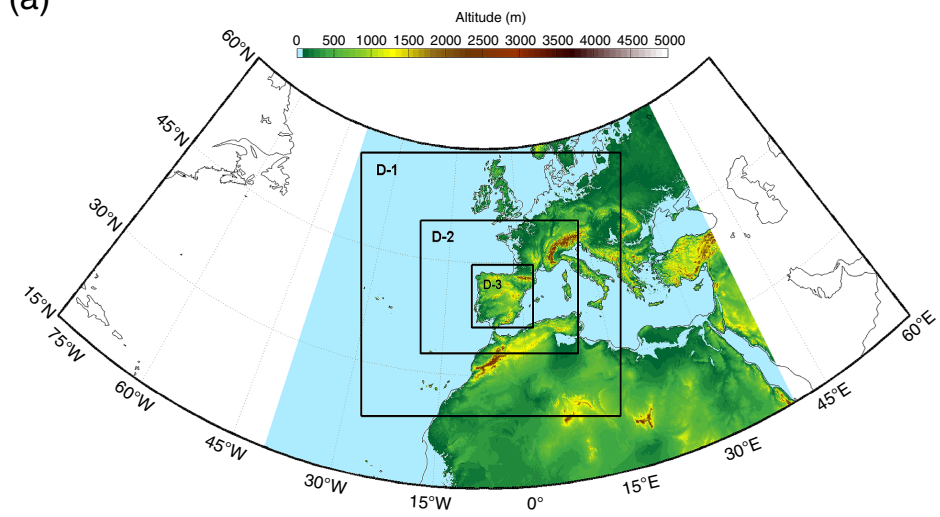

(b)

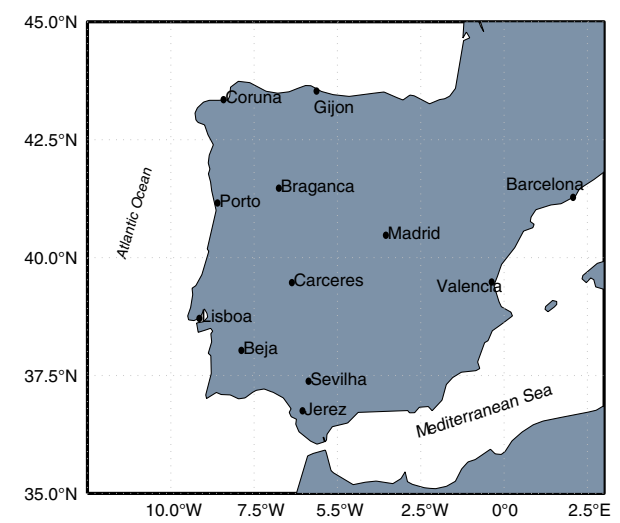

Figure 1. (a) Location of the study area with the nested domains used in WRF simulations. The WRF ran in 2-way nesting mode with increasing domain resolutions of 81 (D-1), 27 (D-2) and $9 \mathrm{~km}$ (D-3); (b) The 12 locations studied. [Colour figure can be viewed at wileyonlinelibrary.com].

years (Frich et al., 2002; Schär et al., 2004; Kysely, 2010; Zuo et al., 2015) as opposed to CSs for which little research has been conducted (Barnett et al., 2012; Peterson et al., 2013; Lhotka and Kysely, 2015).

Recent studies have led to a more elaborate understanding of the key interactions behind the HW's phenomenon (Perkins, 2015). HWs results from the interaction of large-scale processes, like a synoptic situation of a high-pressure persistently located over a region, with small-scale processes such as the soil moisture. Soil moisture - temperature interaction are very complex, particularly if we consider also these interactions via cloud and precipitation but, overall, the feedback appears to be positive that is, dry soil favours warmer temperatures (Vautard et al., 2013). Although, not all pairs of dry soil/anticyclonic weather origin HWs, in particular circumstances HWs can be an amplification of a positive feedback between soil dryness and anticyclone weather. Established this relationship, it is clear that the capability of climate models to simulate HWs also relies on the parameterizations of soil moisture and the not so known physical processes and their interactions between the land-surface and the atmosphere. Another factor is the requirement that regional climate models need boundary forcing fields to drive the models. Downscaled from a coarser resolution grid to a higher resolution grid, these fields must accurately represent the large-scale dynamics in order to reproduce the atmospheric structure at the local scale resolution. Many authors used regional climate models over Europe to study HW's characteristics (Domínguez et al., 2013; Schoetter et al., 2015; Ouzeau et al., 2016). Vautard et al. (2013) extensively studied, for present climate conditions, HW's climate using several simulations from a set of eight different models from the EURO-CORDEX project, while Lau and Nath (2014) examined the synoptic characteristics of HWs for the present climate with projections for future climates.

Many authors have investigated the HWs but only a few have conducted studies on CSs. Moreover, these studies have poorly investigated the waves/spells characteristics or did not inspected climate changes of HWs and CSs properties in the IP. The present study sought to fill the literature review gap concerning the summer HWs and winter CSs over the IP in a climate change scenario, and suggests an approach which is based on HWs and CSs characteristics. The study aims to investigate the variations in the properties of HWs and CSs, as calculated from the given definition by the present authors on the regional climate simulation of two future climate 20 -years periods under the 8.5 Representative Concentration Pathway, RCP8.5 greenhouse gas emission scenario, over the IP. The properties considered in this study are: duration of the HWs/CSs (DUR), recovery factor (RF) and intensity (INT) of HW and CS.

This study is organized as follows. Section 2 describes the data, the methodology used to identify the HWs and the CSs, and the methods employed. Then, the main results and their discussion is performed in Section 3. Finally, in the last section, the conclusions are drawn.

\section{Data and methods}

\subsection{Study area}

The study area is located in the southwestern part of Europe and comprises Portugal and Spain (IP in Figure 1(a)). Its topography varies from the Great Plains in the southwest and the central plateau to complex orographic features in the north-northeast regions. The most notable mountains are Sierra Nevada $(3400 \mathrm{~m})$, located in southern Spain and the Pyrenees $(3500 \mathrm{~m}$ ) in the NE, bordering Spain and France. These orography features and the geographic location of IP, surrounded by the Atlantic Ocean and the Mediterranean Sea, give the Iberian climate some peculiarities.

The North and West regions, largely exposed to the maritime Atlantic winds, have mild summers and wet winters. The southern part is hotter and drier due to the influence of the warm air masses over the Mediterranean Sea and the Sahara desert [for an extended description see the report of AEMet and IM, I.P. at AEMET (2011)]. 


\subsection{Data and model validation}

The Weather Research and Forecast (WRF) model v3.5 (Skamarock et al., 2005) was used to dynamically downscale climate data from the Max Planck Institute Earth System Model (MPI-ESM-LR) to a high-resolution (9-km) climatic grid over IP (Figure 1(a)), for a recent-past climate (1986-2005).

A second set of simulations were performed, using the same regional WRF configuration and as boundary and initial conditions the MPI-ESM-LR simulations, under the assumption of the RCP 8.5 scenario. The scenarios are projections dependent on how much greenhouse gases are expected to be emitted to the atmosphere in the upcoming years. The RCP 8.5 scenario is one of the four developed future climate scenarios where a radiative forcing of $8.5 \mathrm{~W} \mathrm{~m}^{-2}$ is considered, with a steady increase in the gases concentration throughout the 21 st century. This RCP setup is expected to produce an increase in the global-mean near-surface air temperature of $4.5^{\circ} \mathrm{C}$ by the year 2100 relative to the pre-industrial era (Moss et al., 2008).

For this emission scenario, the considered periods of future climate under analysis correspond to a mid-term future, from 2046 to 2065, and a long-term future for the 2081 to 2100 period. The simulation domains vary from a coarser resolution domain (grid-cell of $81-\mathrm{km}$ ), covering the IP and extend west into the North Atlantic Ocean (to better capture the synoptic features), and a high-resolution domain (grid-cell of 9-km) covering the IP region (Figure 1(a)).

The WRF model's physical configuration includes the following parameterizations: WRF single-moment 6-class microphysical scheme (Hong and Lim, 2006); Dudhia shortwave scheme (Dudhia, 1989); RRTMG (Rapid Radiative Transfer Model) longwave radiation model (Mlawer and Clough, 1997); MM5 similarity surface layer scheme (Zhang and Anthes, 1982); Noah Land Surface Model (Chen et al., 2004); Yonsei University Planetary Boundary layer (Hong et al., 2006) and the Grell-Freitas Ensemble scheme for cumulus parameterization (Grell and Freitas, 2013). These set of parametrizations have been used in the operational forecast for Portugal available at the University of Aveiro (http://climetua.fis.ua.pt, Group of Meteorology and Climatology), and in several other studies of extreme precipitation events (Pereira et al., 2013). The WRF model has been applied also in regional climate studies, in a series of sensitivity experiments to microphysics, convection and radiation schemes for the EURO-CORDEX domain, representing the 1990-2008 climate with reasonable fidelity (Katragkou et al., 2015).

The description and assessment of climatic runs of the WRF model forced by the global model MPI-ESM-LR results (WRF-MPI), for the recent-past, applied with the above described configuration are presented by Marta-Almeida et al. (2016).

In the present work, the model evaluation was performed by comparing temperature simulations of the recent-past climate with observations. The dataset used was the EOBS-ECA\&D gridded data. The EOBS dataset consists of a blended ECA\&D station series interpolated to gridded daily observations of temperature. The dataset includes the period starting from 1 January 1950 and ending in 31 December 2016 covering Europe (full description in Haylock et al., 2008). For this study, it has been used the EOBS version 14 with a regular horizontal resolution of $0.25^{\circ} \times 0.25^{\circ}$. Among the three nested domains, we choose to evaluate and analyse the inner domain with 9-km grid-cell resolution for a better description of the surface fluxes influencing the temperature fields. This permits, to gain information when remapping the $9 \mathrm{~km}$ WRF results into the EOBS grid. The remapping uses the nearest neighbour method in order to avoid extra smoothing from the interpolation methods. The WRF's validation was made by comparing the mean summer/winter temperature fields, namely the simulated 90 th and 10 th percentiles. A second set of observations, the Spanish dataset Spain02 version 4 with $0.11^{\circ}$ horizontal resolution was used to validate the spatial distribution of the summer and winter climatological 90th and 10th percentiles (Herrera et al., 2016).

The above mentioned twelve locations are scattered over the IP and are representative of the different climate regions (Brunet et al., 2007; AEMET, 2011). They were chosen to study the properties of the HWs and the CSs and their respective change under a climate change scenario (Figure 1(b)). All locations are large metropolitan areas of greatest importance in Portugal and Spain namely, Lisboa, Porto, Madrid, Barcelona, Valencia, Sevilha, Bragança, Beja, Gijón, Cáceres, Jérez and Corunha. The selection was based on the fact that cities gather the population, the principal service activities and many of them are ill-equipped for climate change adaptation when focusing on infrastructure and building. Maximum and minimum near-surface daily atmospheric temperatures were extracted for the 12 locations using the closest model 9-km grid-point at each location. This procedure was applied for each 20-year period.

\subsection{HW and CS definition}

Despite the existence of numerous studies of HWs, there is not a universal definition for it. Usually, CSs are defined similarly to the HWs. The underlying reasons are, (1) HWs and CSs are dependent of local climatology. What might be described as an extreme in a temperate climate over mid-latitude regions, may not be in a tropical regions, (2) there are numerous methods to count for HWs and CSs. These methods can be grouped into two major categories. The first group of methods builds on the selection of the temperature threshold and the minimum number of days that a HW must have. Some methods are based on a fixed critical value of the daily maximum temperature set prior to the analysis, for example $30^{\circ} \mathrm{C}$, with a fixed minimum number of consecutive days (Hansen et al., 2008; Kysely, 2010). Others methods have chosen to associate the temperature threshold to the local climatology, either by using the climatological temperature plus a fixed value (Frich et al., 2002; Perkins, 2015) or using a percentile based threshold (Russo et al., 2014). In these methods, a HW is considered when the daily temperature exceeds the critical value for a period of a fixed number of consecutive 
days. The second group of methods is based on climatic indicators (Frich et al., 2002; Zhang et al., 2011; Russo et al., 2014) such as the heat index that uses the maximum temperature and relative humidity (Robinson, 2001). The climatic indices are built offering the possibility of comparison among regions with different climatologies. The method chosen, as well as the set of temperature threshold and the number of consecutive days considered, influences the total number of identified waves (Tong et al., 2010).

In this study, HWs/CSs are defined as the period of, at least, three consecutive days in which the maximum/minimum temperature is equal or above/below the daily threshold for the 20-years reference period of the recent-past climate (1986-2005).

The minimum number of consecutive hot days required to be considered as $\mathrm{HW}$ varies among studies. For example, Ouzeau et al. (2016) define the HW duration as dependable of some pre-defined temperature thresholds, whereas Schoetter et al. (2015) relate HWs and energy supply and define a HW, over Western Europe, as an event of at least three days. In this study we choose a minimum of three consecutive days.

The daily threshold temperature is obtained by calculating the climatological daily 90 th/10th percentile of the daily maximum/minimum temperature series, centred in a 31-day window as detailed by Russo et al. (2014). The threshold temperature, $T_{\text {thres }}$, for a particular day, $d$, can be defined as the $90 \mathrm{th} / 10$ th of the temperature series as:

$$
T_{\text {thres }, d}=U_{\text {start year }}^{\text {end year }} U_{\text {day-15 }}^{\text {day }+15} T_{90 \text { th } / 10 \text { th, day }}^{\text {year }}
$$

where $U$ denotes the union of the 90th/10th percentile of the maximum/minimum temperature in a 31-day window around the day, $d$.

Yielding a HW definition as:

$$
\mathrm{HW}=T_{\max } \geq T_{\text {thres }, d} \text { for } \geq 3 \text { consecutive days }
$$

and for CS:

$$
\mathrm{CS}=T_{\text {min }} \leq T_{\text {thres }, d} \text { for } \geq 3 \text { consecutive days }
$$

For each one of the 365 calendar days, $d$, the 90th/10th percentile is calculated considering all data on a window of 31 days ( 15 days on either side) using the data of 1986-2005. Instead of using a 31-day window for calculating the daily 90th/10th percentile for each year and then average the daily percentile for the 20-years, in this study, we consider a 31-day moving window spanning the 20 -year period. So, the value obtained for day, $d$, will be the percentile of a 20 -year set of 31 days. Hence, the use of the climatologic term on the definition of the daily threshold series. This gives a sample of 620 days used to calculate the daily climatological 90th/10th percentile threshold for each calendar day. The daily climatological threshold series follows closely the seasonal cycle and the range of temperatures varies with location. Namely, the southern locations exhibit warmer temperatures than those located in the north as reported in literature (Fernández-González et al., 2014).

\subsection{Spatial correlation and bias}

To compare spatial patterns of waves' characteristics, the spatial correlation has been calculated. The procedure is similar to calculating temporal correlation but the pairs of values are those for the value of the variable at the same model grid-point, for each variable field. Also, the mean spatial bias has been evaluated by calculating the difference between the area-averaged mean of the two variable fields.

2.5. Changes in the probability density functions (PDF) of the wave's characteristics

The threshold series were calculated for all model grid-points. Subsequent, all HWs/CSs were identified at all grid points as well as their averaged properties. To save space, the following analysis is performed only for the 12 locations. The individual maximum/minimum temperature series were inspected for HW and CS events. Each time the temperature and the duration met the HW or the CS criteria, three parameters were calculated to describe the characteristics of the waves:

\section{- duration of the HWs/CSs}

- recovery factor $\left\{\left(\frac{1}{n}\right) \sum_{i=1}^{n}\left|T_{\max }-T_{\min }\right|\right\}$

- intensity of HW $\left\{\left(\frac{1}{n}\right) \sum_{i=1}^{n}\left|T_{\text {thres }}-T_{\max }\right|\right\}$

- intensity of CS $\left\{\left(\frac{1}{n}\right) \sum_{i=1}^{n}\left|T_{\text {thres }}-T_{\min }\right|\right\}$

where $n$ is the number of days covering an event. During the HW episodes, the minimum temperature can be important because during nighttime the human body is able to recover from the excess of heat during daytime. Some studies reported a link between the high nighttime temperatures and fatalities (Karl and Knight, 1997).

In the present work, during the HW/CS events, the absolute difference of the day and night temperature was calculated as a measure of the possible relief from the daytime heat and, henceforth, is designated the recovery factor (RF). Karl and Knight (1997) state that the body tends to accommodation after the first days of the wave, so variations in this difference can establish how well the body can adjust to future changes. Small values of RF indicate high values of minimum temperature. To examine the severity of the HW, the absolute difference among $T_{\max }$ and $T_{\min }$ with $T_{\text {thres }}$, for the duration of the HW, was calculated. This amplitude acts like an intensity (INT) measure of the wave. When considering the deaths caused by HWs, their INT assumes a relatively more important role than duration (Zuo et al., 2015). These characteristics were chosen considering the regional differences among regions within the IP. The events were grouped by season and the analysis focuses on the summer and winter months, 


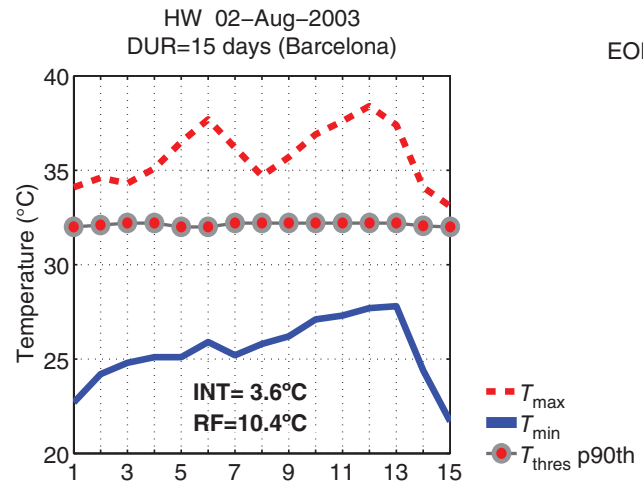

HW INT DUR $=15$ days EOBS 2-Aug-2003 to 16-Aug-2003
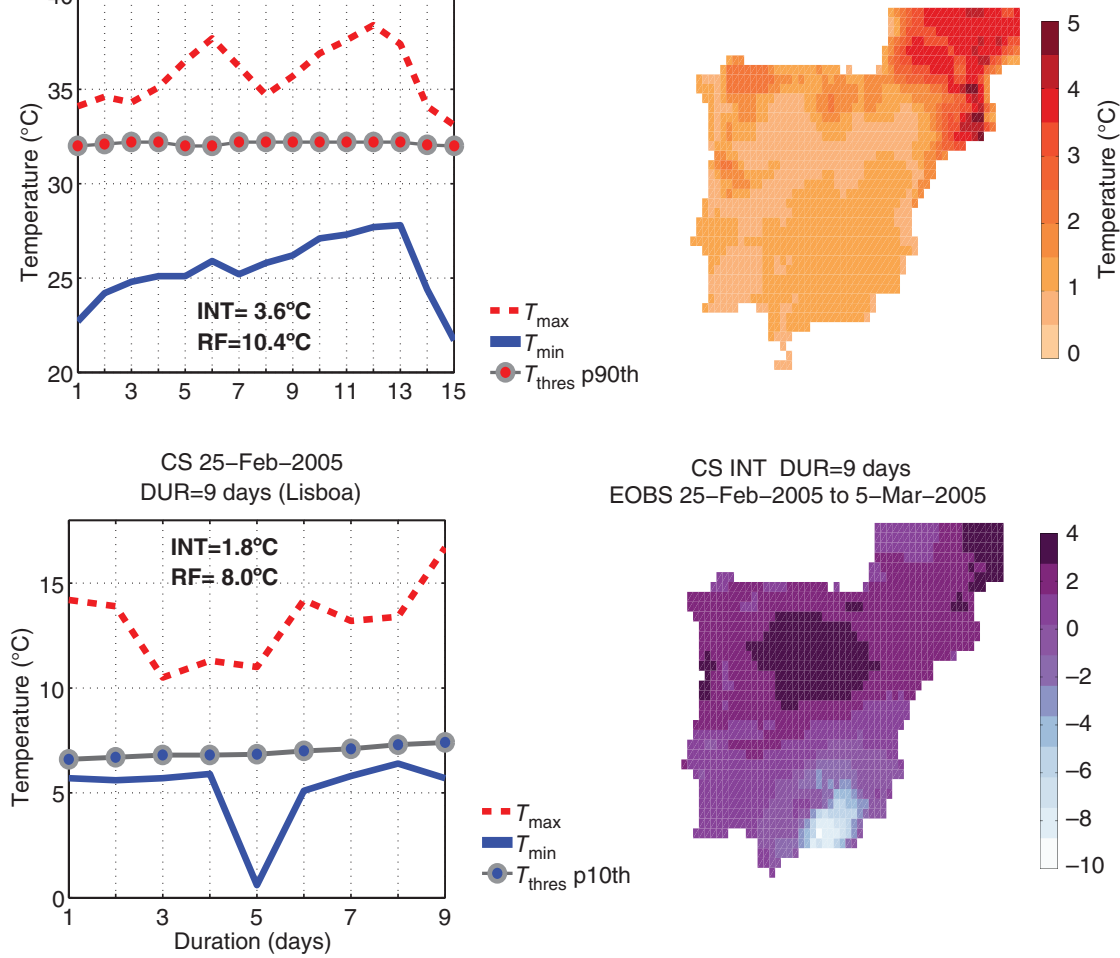

CS INT DUR=9 days EOBS 25-Feb-2005 to 5-Mar-2005

Figure 2. Examples of observed HW (top panel) and CS (bottom panel) over the Iberian Peninsula. The left column represents the days with wave at a single location and the respective maximum temperature (dashed line), minimum temperature (solid line) and the threshold used (circles). For each wave, INT and RF are displayed. The figures in the right column display INT. The top right is the $2003 \mathrm{HW}$ over Iberia and the bottom right is the 2005 CS over Iberia (positive values correspond to areas affected by the wave). For example, for the $2003 \mathrm{HW}$, Barcelona experienced INT of $3.6^{\circ} \mathrm{C}$ and $\mathrm{RF}$ of $10.4^{\circ} \mathrm{C}$. [Colour figure can be viewed at wileyonlinelibrary.com].

despite the fact that HWs and CSs may occur at any time of year. However, it is in the summer and winter months that HWs and CSs effects are mostly felt, respectively. Summer is defined from 1 June to 31 August minus and plus 3 days, respectively, to be sure to include waves that might fall in the beginning or the end of the season. Winter is defined as the period that starts at 1 December and ends at 28 February. The same procedure was applied for the two periods representative of a future climate state namely, the mid-future (2046-2065) and the long-term climate (2081-2100), but in these time slices the season was extended to include longer waves that started in late spring or late autumn but last into the selected summer or winter months.

Figure 2 presents an application of the method for the identification of two observed waves, one HW and one CS, over the IP. The daily climatological 90 th/10th percentile (grey circle line) series are represented by the smooth lines with little daily variation. The HW is the one that occurred in August of 2003 which caused many heat-related deaths in the IP. The HW is identified as a cluster of consecutive days with maximum temperature (red dashed line) above the threshold. The opposite behaviour is observed for the $\mathrm{CS}$, where the minimum temperature (blue line) is below the threshold. The mean intensity values were higher in the north-northeast zone of the PI, a region with colder maximum temperatures, with mean deviations between 4 and $6{ }^{\circ} \mathrm{C}$. The $2003 \mathrm{HW}$ INT presents a spatial gradient opposite to the maximum temperature; INT is higher in the lower temperature regions. This gradient is opposite in the cold waves. There is an intensification of the CS in lower temperature zones.

To evaluate the changes in the properties of the waves, their characteristics, namely the mean value and the 95th percentile were calculated. Also, the PDFs of each parameter were estimated using a non-parametric procedure, namely, the Kernell density estimator (KDE), for the different periods. The KDE returns a probability density estimate, $f$, for the sampled points (Bowman and Azzalini, 1997). The estimator is defined by:

$$
\widehat{f}_{h}(x)=\frac{1}{n h} \sum_{i=1}^{n} K\left(\frac{x-x_{i}}{h}\right) ;-\infty \leq x \leq+\infty
$$

where $n$ is the sample size, $K$ is the Kernel function, and $h$ is the bandwidth. Recently, Forzieri et al. (2016) used the same non-parametric estimator to found out return periods for HWs and CSs, and to identify regions that are most exposed to multiple climate hazards. The series were de-trended with the methodology established by (Della-Marta et al., 2007). The PDFs for the past-recent climate and the two projections for a mid-term climate and a long-term climate where assessed for differences using the two-sample Kolmogorov-Smirnov hypothesis 
EOBS

90th JJA

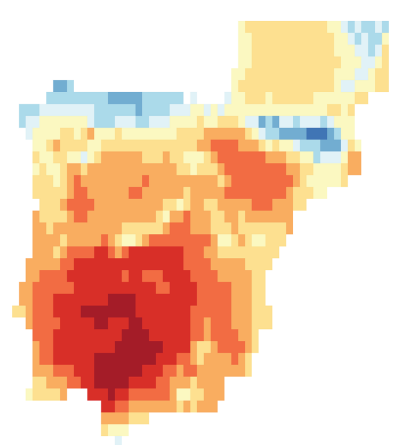

EOBS

10th DJF

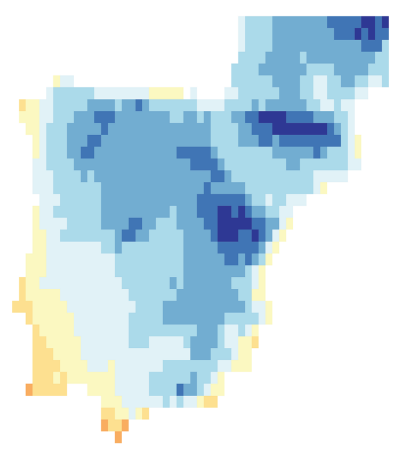

Spain02

90th JJA

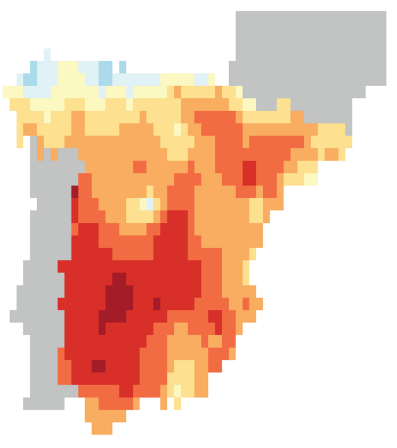

WRF-MPI

90th JJA

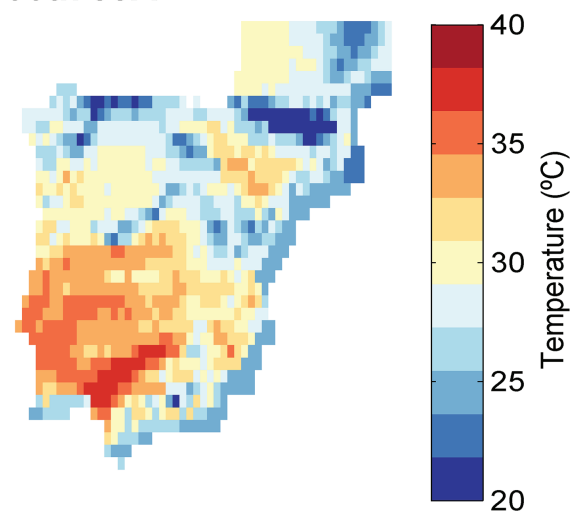

WRF-MPI 10th DJF

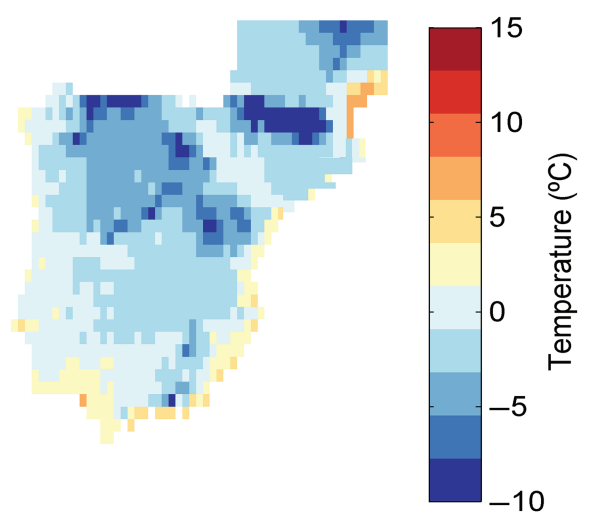

Figure 3. Observed mean 90th/10th percentiles temperature fields for HWs/CSs from the EOBS and Spain02 gridded data sets and the respective simulated fields for the 1986-2005 period. The observations and the model simulations were remapped to the observations grid. The Spain02 dataset (middle figures) does not have data for Portugal and France (grey coloured). [Colour figure can be viewed at wileyonlinelibrary.com].

Table 1. Spatial correlation and mean spatial bias between the mean EOBs and WRF-MPIh HW/CS numbers and characteristics. Correlation within the interval of 0.10 to 0.30 are considered weak, moderate if within 0.30 to 0.70 interval and strong if above 0.70 .

\begin{tabular}{|c|c|c|c|c|c|c|c|c|c|c|}
\hline \multirow[b]{2}{*}{ HW EOBS versus WRF-MPI } & \multicolumn{2}{|c|}{ DUR (days) } & \multicolumn{2}{|c|}{ INT $\left({ }^{\circ} \mathrm{C}\right)$} & \multicolumn{2}{|c|}{$\mathrm{RF}\left({ }^{\circ} \mathrm{C}\right)$} & \multicolumn{2}{|c|}{$N$ waves } & \multicolumn{2}{|c|}{$N$ days (days) } \\
\hline & 0.43 & $* * *$ & 0.37 & $* * *$ & 0.46 & $* * *$ & 0.28 & $* * *$ & 0.30 & $* * *$ \\
\hline & & -0.22 & & 0.05 & & 3.29 & & 0.14 & & -3.07 \\
\hline \multirow{2}{*}{ CS EOBS versus WRF-MPI } & 0.34 & $* * *$ & 0.48 & $* * *$ & 0.17 & $* * *$ & 0.04 & 0.25 & 0.17 & $* * *$ \\
\hline & & -0.11 & & 0.12 & & 2.83 & & 1.29 & & 4.33 \\
\hline
\end{tabular}

The significance threshold was set at alpha 0.05 and 0.01 , so any $P$-values less than alpha level are to be considered significant. The mean spatial bias is represented by the bold figures and is the difference between the EOBS and WRF-MPIh for the 1986-2005 period. Differences for Ndays and DUR are per HW/CS and for $N$ waves per summer/winter. $* * 0.01<P$-values $<0.05$. *** $P$-values $<0.01$.

test (Massey, 1956). The test is non-parametric and evaluates the differences between two distributions using the maximum absolute difference between the respective cumulative distribution functions. The test statistic is:

$$
D^{*}=\max _{x}\left|F_{1}(x)-F_{2}(x)\right|
$$

where $F_{1}$ and $F_{2}$ are the distributions to be compared. The test rejects the null hypothesis here indicated by $H=1\left(F_{1}\right.$ and $F_{2}$ are from the same distribution) if the $p$-value is less than the $\alpha$ level. The statistical significance was performed at the $0.05 \alpha$ level.

\section{Results and discussion}

\subsection{WRF model validation}

The historic simulations were evaluated against the EOBS and Spain02 gridded observations in order to assess the ability of the model in reproducing the temperature fields. The model WRF-MPI is able to reproduce the temperature's spatial structure when compared with the gridded observations datasets. The annual simulations identify a hotter region in southern Spain and the northern Peninsula colder region (analysed but not shown). Also, the 90th and the 10th percentile were compared since these are the 
most relevant to study $\mathrm{HWs} / \mathrm{CSs}$. The daily climatological summer and winter thresholds of the 90th and the 10th percentiles, respectively, are shown in Figure 3 for the EOBS, Spain02 and WRF-MPI. There is a good agreement amongst the spatial patterns of the datasets. The seasonal cycle is also well reproduced by the model, as well as the mild summer/winter temperatures near the coastline. The mean summer EOBS 90th percentile is higher than the simulated which is also evident in the annual probability distributions of the summer maximum temperature (analysed but not shown).

To evaluate the ability of the model in successfully simulating the waves, the total number of waves ( $N$ waves), total waves' number of days (Ndays), their average duration (DUR in days) and intensity (INT in ${ }^{\circ} \mathrm{C}$ ) were compared with those derived from EOBS - ECA\&D data. This was performed for each model grid-point. After discarding the points over the ocean, 1233 valid grid points were retained. We should highlight here that the number of HWs/CSs and the related characteristics (i.e. $N$ days, DUR and INT) are evaluated using the respective threshold of each dataset (i.e. EOBS and WRF-MPI). This would somewhat minimize the bias identified in the thresholds (i.e. 90th and 10th percentiles shown in Figure 3) of both datasets. Spatial correlations and the mean spatial bias were computed between EOBS and WRF-MPI, for each wave characteristic. These are shown in Table 1. The correlation figures within the interval of 0.10 to 0.30 are considered weak, moderate if within 0.30 to 0.70 interval and strong if above 0.70. The significance threshold was set at alpha 0.05 and 0.01 , so any $P$-values less than alpha are considered significant. In general, a positive bias is observed for all the waves' characteristics except for $N$ days and DUR, which are overestimated by the model. Some of the major differences are accompanied by low correlations and are related with the total CS Ndays and the RF.

Figure 4 displays the spatial patterns of the mean summer HWs' and winter CSs' characteristics, namely INT, $N$ waves and Ndays, for EOBS and WRF-MPI. The spatial pattern of the mean HW INT is in opposition with the temperature pattern, with high values in the north-western region of the IP, and with values close to zero near the Mediterranean areas. Since, INT of the HW is defined as the departure from the 90th percentile, this indicates that areas with mild north summers experience more intense HW. Overall, the simulations provide a good representation of the recent-past climate moderately related to the observations ( $r=0.34$ to $r=0.43$, Table 1$)$. Neither the coastal effect of the ocean nor the continental regions seem to influence the INT of the waves. The spatial distribution of the CSs' INT follows the spatial gradient of temperature suggesting that areas with lower temperature experience more intense CS. The spatial distribution of the CS $N$ waves observed during the 20 -years period over western coastal areas is reasonably well reproduced, with the western coastal areas registering more waves (HW and CS) and the central area of IP with fewer waves. The Central region of the IP shows weaker correlations between the parameters calculated based on observations and model
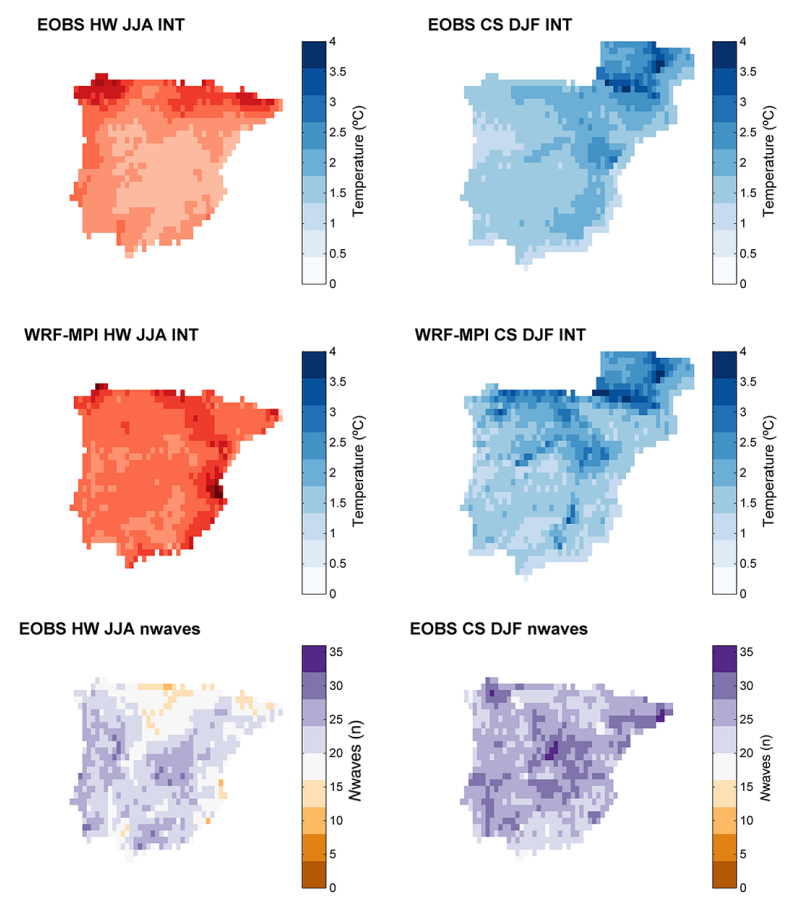

EOBS CS DJF nwaves
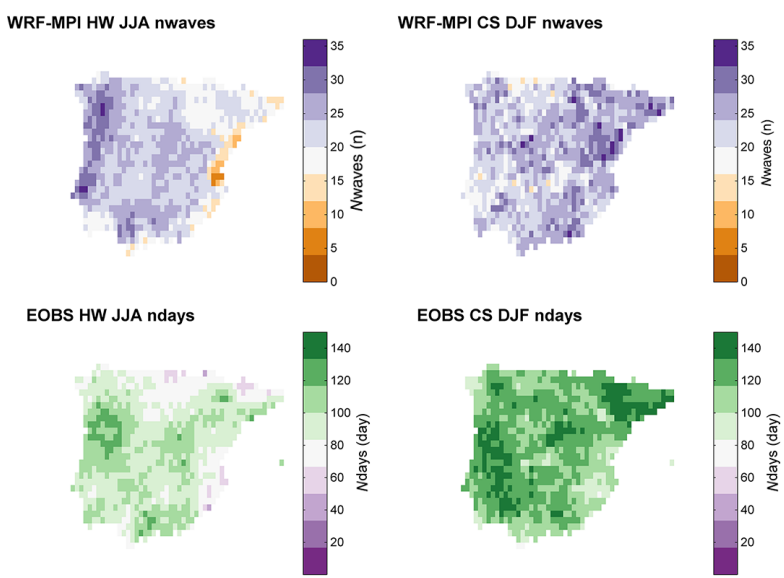

EOBS CS DJF ndays
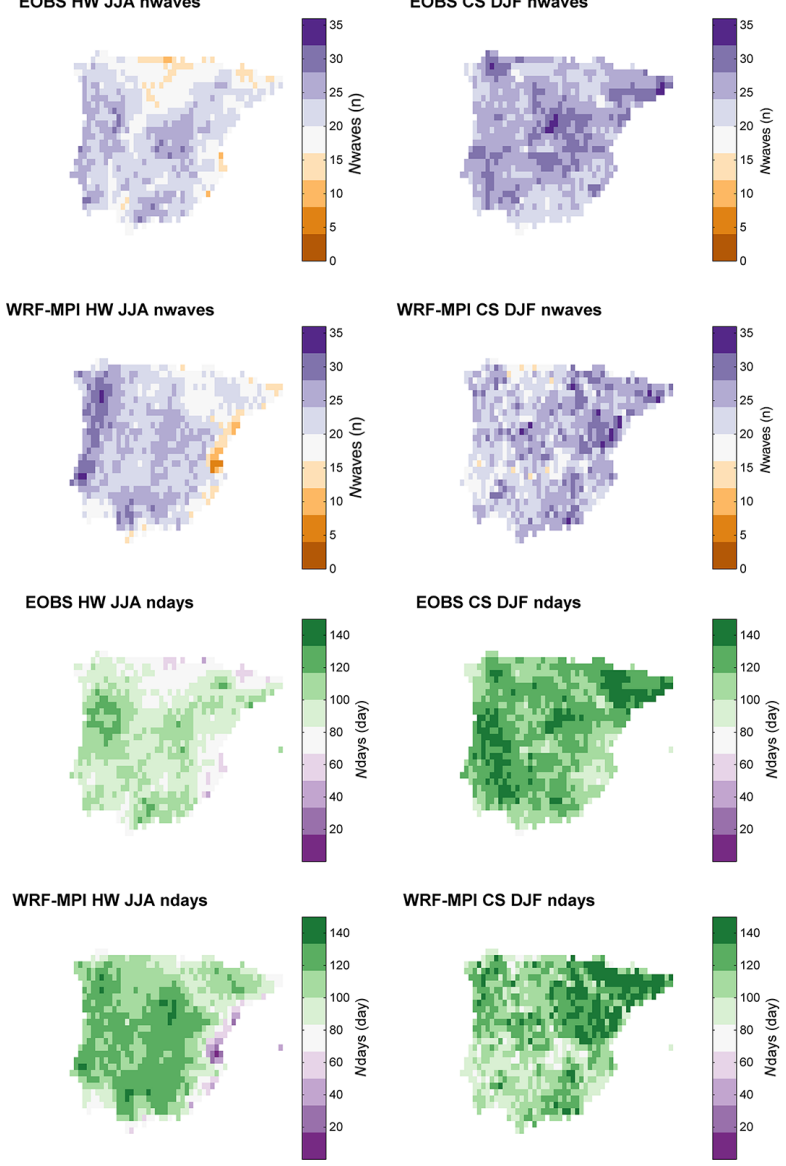

WRF-MPI CS DJF ndays

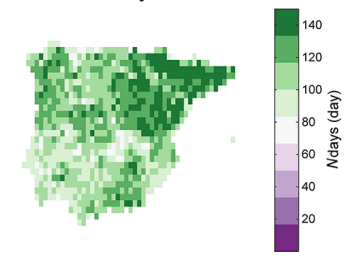

Figure 4. Mean summer HWs' and winter CSs' characteristics, namely INT, $N$ waves and Ndays, for EOBS and WRF-MPI for the 1986-2005 period. $N$ days and DUR are per HW and $N$ waves per summer/winter. [Colour figure can be viewed at wileyonlinelibrary.com].

results. Overall, significant moderate relations were found between the EOBS and the WRFs simulations for the recent-past climate.

\subsection{HWs}

This section is concerned with the PDFs of HWs properties to characterize the general distribution changes amongst the three climate periods simulated by the WRF-MPI model. Hereinafter, and contrary to what was done in the validation section, the comparison of HW/CS numbers 

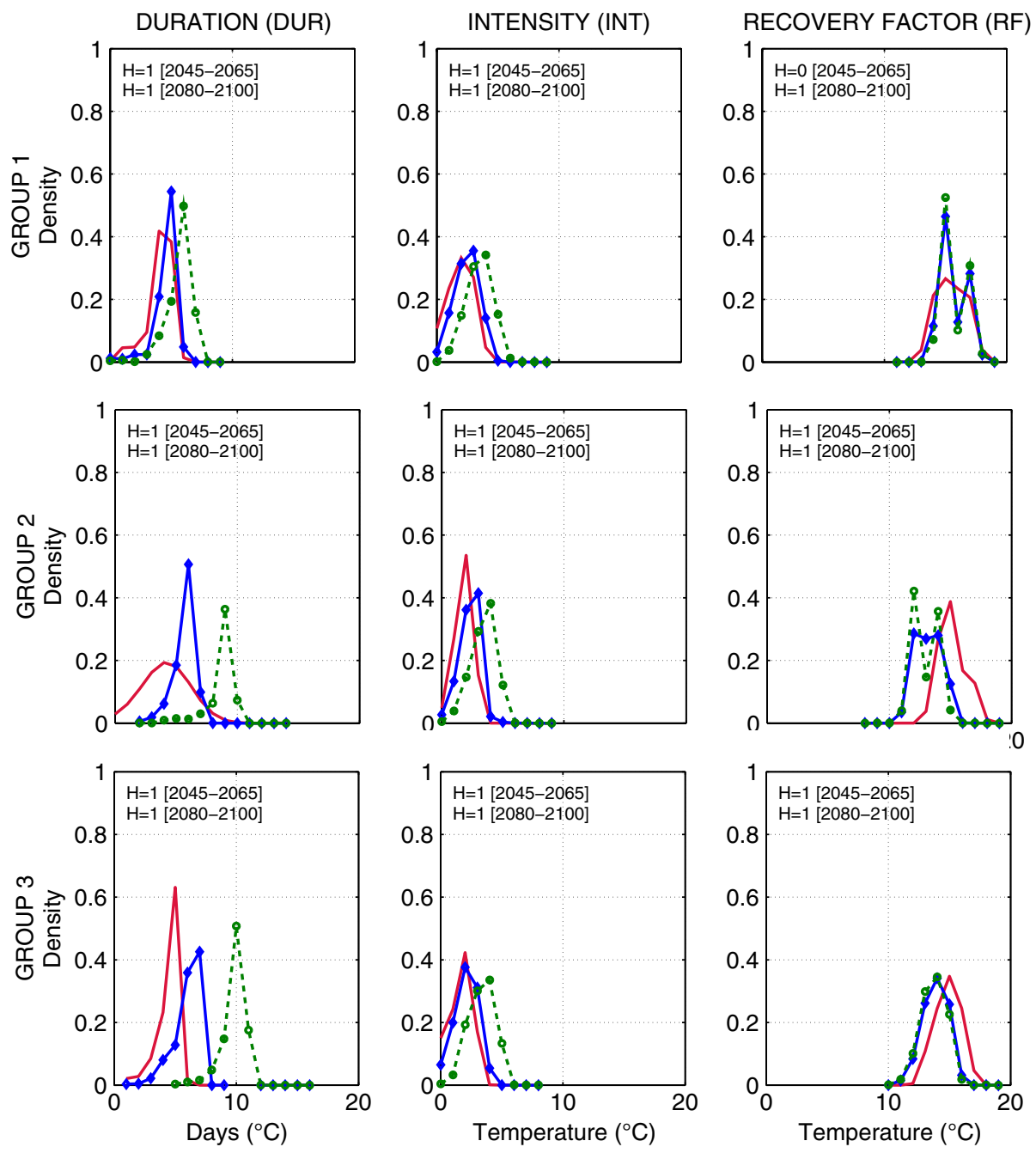

$-1986-2005+2046-2065 \cdot \cdot-2081-2100$

Figure 5. PDFs of summer HW DUR, RF and INT for three locations of each group referred in Table 1 . If $H=1$, the Kolmogorov-Smirnov test rejects the null hypothesis at the $5 \%$ significance level (i.e. statistically significant changes between distributions), and 0 otherwise. [Colour figure can be viewed at wileyonlinelibrary.com].

and characteristics between future and present climates simulated by the WRF-MPI uses the threshold of the simulated present climate. This was done since we wanted the wave's characteristics to quantify the change relative to the present climate. The main objective of this study is, therefore, to anticipate adaptation measures relative to what is the present reality. The strongest HWs are located in the extreme of the PDFs and are, therefore, not clearly shown in the PDFs (figure 5). As such, the 90th percentile of the properties' distributions were calculated. The 12 locations were aggregated into three groups, according to the similarities of the simulated changes (future minus recent-past) in the wave's duration PDF profile (Table 2). Waves with similar PDFs were grouped. That is, we are grouping characteristics of waves and not climatic regions. For example, for Porto and Barcelona, the probability density of wave characteristics are similar, and so they are grouped together. The results of the waves' properties of each group were aggregated into a single distribution for further analysis on significant statistical differences between recent-past climate and future climate scenario time slices. The main characteristics of these PDFs, namely, mean, and 95th percentile are shown for HWs, for all locations, climate periods and properties (i.e. DUR, RF and INT), in Table 3. The number of waves and days of waves are also shown.

Figure 5 presents the group PDFs of DUR, RF and INT for HWs in the three climate periods. Statistical significant PDF changes between the two future periods and the recent-past are represented by $H=1$ in all plots of Figure 5. In general, the PDFs of DUR and INT shift to the right for the three groups, whilst the RF shift to the left. This represents an increase of central measures such as the average and median for DUR and INT and a reduction for RF. A decrease of variance is mostly notable for DUR for group 2 locations. These future changes are greater for the long-term future. These changes represent harsher conditions in terms of high-temperature related health risks. All changes are statistically significant, except 
Table 2. Distribution of the locations in groups of similar waves' characteristics.

\begin{tabular}{ll}
\hline Group & Location \\
\hline 1 & Lisboa and Corunha \\
2 & Bragança, Beja, Porto, Barcelona, Gijón and Valencia \\
3 & Madrid, Cáceres, Sevilha and Jerez \\
\hline
\end{tabular}

for the mid-term future for RF in group 2 and for INT in group 3 .

Table 3 shows HWs statistics, particularly extreme ones (i.e. p95) since they are not identified in the PDFs shown in Figure 5 climate periods and properties (i.e. DUR, RF and INT). Also shown is the number of HWs and Ndays for which the statistical significant (\%) future changes are shown in bold.

The number of HWs increases for the future periods particularly for the long-term future. The same is true and more evident for $N$ days. The only particularity is a smaller increase in the number of HWs for Barcelona, for the long-term future, when compared with the mid-term future. This is not relevant since the number of wave-days follows the expected pattern of largest increases for the long-term future. All these changes are statistically significant $(5 \%)$ and mean that, on average, many future summer days (mostly for long-term future) will be HW days, particularly for Barcelona, Cáceres and Sevilha. All differences of the number of HWs and $N$ days between the future periods and the recent-past are statistically significant (5\%). The only exception is for HWs numbers for Gijón.

These results show consistency with those found in literature, where the probability of events, like that of 2003, were identified as increasing (Barriopedro et al., 2011), or the clearly warming of Europe in a far future for every season (Carvalho et al., 2016). Also, this pattern of increase was observed by Della-Marta et al. (2007), which showed a positive trend in the hot days and HW, in the IP,

Table 3. Statistics of the HWs properties', namely Nwaves, Ndays, mean, and 95th, percentile for DUR, RF and INT.

\begin{tabular}{|c|c|c|c|c|c|c|c|c|c|}
\hline \multirow[t]{2}{*}{ Location } & & \multirow[t]{2}{*}{$N$ waves } & \multirow[t]{2}{*}{$N$ days } & \multicolumn{2}{|c|}{ Duration (days) } & \multicolumn{2}{|c|}{ Recovery factor $\left({ }^{\circ} \mathrm{C}\right)$} & \multicolumn{2}{|c|}{ Intensity $\left({ }^{\circ} \mathrm{C}\right)$} \\
\hline & & & & Mean & p95 & Mean & p95 & Mean & p95 \\
\hline \multirow[t]{3}{*}{ Braganca } & $1986-2005$ & 1.24 & 5.05 & 4.08 & 6.00 & 15.55 & 17.19 & 1.94 & 4.02 \\
\hline & $2046-2065$ & 3.90 & 22.00 & 5.63 & 11.20 & 14.59 & 16.45 & 2.30 & 4.53 \\
\hline & $2081-2100$ & 6.52 & 55.81 & 8.55 & 22.95 & 14.85 & 16.80 & 3.50 & 5.65 \\
\hline \multirow[t]{3}{*}{ Beja } & $1986-2005$ & 1.33 & 5.10 & 3.82 & 7.20 & 17.38 & 20.18 & 1.67 & 4.20 \\
\hline & $2046-2065$ & 4.33 & 23.86 & 5.51 & 10.95 & 16.86 & 19.70 & 2.25 & 4.11 \\
\hline & $2081-2100$ & 6.52 & 57.71 & 8.85 & 18.65 & 16.79 & 19.59 & 3.17 & 5.51 \\
\hline \multirow[t]{3}{*}{ Porto } & $1986-2005$ & 1.38 & 5.43 & 3.93 & 8.05 & 14.23 & 16.16 & 2.10 & 3.71 \\
\hline & $2046-2065$ & 3.10 & 15.71 & 5.08 & 11.00 & 13.69 & 15.97 & 2.57 & 4.30 \\
\hline & $2081-2100$ & 5.00 & 32.71 & 6.54 & 13.25 & 14.39 & 16.56 & 3.76 & 6.41 \\
\hline \multirow[t]{3}{*}{ Lisboa } & $1986-2005$ & 1.33 & 5.71 & 4.29 & 8.00 & 17.82 & 20.28 & 2.16 & 4.38 \\
\hline & 2046-2065 & 3.57 & 16.76 & 4.69 & 9.50 & 17.09 & 19.59 & 2.58 & 4.35 \\
\hline & $2081-2100$ & 5.57 & 33.24 & 5.97 & 12.00 & 17.10 & 19.62 & 3.71 & 6.90 \\
\hline \multirow[t]{3}{*}{ Barcelona } & 1986-2005 & 0.67 & 2.52 & 3.79 & 8.80 & 8.67 & 11.47 & 1.75 & 3.17 \\
\hline & $2046-2065$ & 5.29 & 36.86 & 6.97 & 15.95 & 7.10 & 9.00 & 1.65 & 2.94 \\
\hline & $2081-2100$ & 4.86 & 80.24 & 16.52 & 60.40 & 6.91 & 8.71 & 2.19 & 3.67 \\
\hline \multirow[t]{3}{*}{ Madrid } & $1986-2005$ & 1.24 & 5.71 & 4.62 & 8.60 & 12.76 & 14.38 & 1.72 & 3.50 \\
\hline & $2046-2065$ & 4.76 & 30.71 & 6.45 & 13.50 & 12.00 & 13.78 & 2.11 & 3.69 \\
\hline & $2081-2100$ & 6.05 & 66.48 & 10.99 & 30.00 & 12.02 & 13.86 & 3.46 & 5.90 \\
\hline \multirow[t]{3}{*}{ Corunha } & $1986-2005$ & 1.14 & 4.43 & 3.88 & 6.90 & 9.84 & 11.23 & 3.13 & 5.37 \\
\hline & $2046-2065$ & 2.14 & 10.48 & 4.89 & 11.25 & 9.48 & 12.64 & 3.68 & 6.36 \\
\hline & $2081-2100$ & 3.00 & 15.62 & 5.21 & 10.35 & 9.45 & 11.75 & 4.27 & 7.07 \\
\hline \multirow[t]{3}{*}{ Cárceres } & 1986-2005 & 1.38 & 5.95 & 4.31 & 7.05 & 15.15 & 17.76 & 1.57 & 3.62 \\
\hline & $2046-2065$ & 4.76 & 28.29 & 5.94 & 13.00 & 14.39 & 16.68 & 2.17 & 4.21 \\
\hline & $2081-2100$ & 6.14 & 62.00 & 10.09 & 20.25 & 14.45 & 16.74 & 3.38 & 5.51 \\
\hline \multirow[t]{3}{*}{ Sevilha } & $1986-2005$ & 1.57 & 6.52 & 4.15 & 6.00 & 18.70 & 20.98 & 1.61 & 3.62 \\
\hline & $2046-2065$ & 4.86 & 29.14 & 6.00 & 13.40 & 17.69 & 20.60 & 2.20 & 3.81 \\
\hline & $2081-2100$ & 6.52 & 66.86 & 10.25 & 29.30 & 16.93 & 19.98 & 2.94 & 5.39 \\
\hline \multirow[t]{3}{*}{ Gijón } & $1986-2005$ & 0.86 & 2.81 & 3.28 & 5.00 & 12.44 & 16.61 & 4.52 & 10.20 \\
\hline & $2046-2065$ & 1.52 & 7.33 & 4.81 & 11.00 & 9.97 & 16.10 & 3.76 & 9.39 \\
\hline & $2081-2100$ & 2.90 & 12.52 & 4.31 & 7.45 & 8.30 & 11.86 & 3.24 & 7.28 \\
\hline \multirow[t]{3}{*}{ Valencia } & $1986-2005$ & 0.48 & 1.62 & 3.40 & 4.00 & 8.95 & 11.40 & 3.23 & 7.41 \\
\hline & $2046-2065$ & 2.24 & 10.90 & 4.87 & 10.30 & 7.01 & 10.04 & 2.35 & 5.13 \\
\hline & $2081-2100$ & 6.00 & 45.19 & 7.53 & 21.80 & 5.75 & 9.21 & 2.13 & 5.13 \\
\hline \multirow[t]{3}{*}{ Jerez } & $1986-2005$ & 1.19 & 5.00 & 4.20 & 8.25 & 16.09 & 17.96 & 1.76 & 3.51 \\
\hline & $2046-2065$ & 4.10 & 22.19 & 5.42 & 11.20 & 15.23 & 16.93 & 2.19 & 4.19 \\
\hline & $2081-2100$ & 7.14 & 55.10 & 7.71 & 17.00 & 14.63 & 17.19 & 2.80 & 5.37 \\
\hline
\end{tabular}

The mean $N$ waves and $N$ days were tested using the $T$-test at $\alpha=0.05$ under the null hypothesis that the samples come from independent random samples with equal means, and equal, but unknown, variances. If the value is highlighted (bold) the test rejects the null hypothesis at the $5 \%$ significance level. $N$ days and DUR are per HW and $N$ waves per summer/winter. 
for the period of 1880 to 2005 , as a response to changes in the mean and variance of the daily summer maximum temperature.

The frequency of HW's DUR will increase for all locations. This is true for average and long durations (i.e. percentile). For the long-term, the average DUR of HWs will increase by more than twofold in many locations, particularly for Barcelona, Cáceres and Sevilha. The trend is also characterized by highest increases for the long-term future, except for Corunha and Gijón which are the northernmost and coolest locations. Highest HWs' DUR will also increase their frequency with Barcelona registering $1 \%$ of $\mathrm{HWs}$ occurring during a great part of summer.

The enhanced frequency, accounted by a shift in the mean can explain the differences between a long-term climate and a recent-past climate. Some authors (Barriopedro et al., 2011; Tomczyk and Bednorz, 2016), suggest that it is possible, in a future scenario, that a more persistent atmosphere can originate more extreme temperatures and more persistent HWs, during the summer season. Regarding RF, the hypothesis of expecting less frequent favourable values (i.e. higher $T_{\max }-T_{\min }$ daily values) is somewhat confirmed. That is, the extreme percentiles and the mean decrease, which is also evident from a shift of the PDFs for the future towards left. The RF decreases are related to higher increases of minimum temperature rather than increases in maximum temperature. This result is in line with the projected decrease in the annual occurrence of cold nights together with a significant increase of warm nights presented in Zhang et al. (2011).

Overall, the differences between the future climates and the recent-past climate are significant $(5 \%)$. This means that, for the future, the recovery factor decreases, contributing to aggravated heat-related health impacts. The cause is associated with a higher increases in $T_{\min }$ (i.e. at night) than in $T_{\max }$ (i.e. at daytime). For the $\mathrm{HW}$ average INT, future climates will register increases with the exception of Gijón and Valencia. For the extreme percentiles, the general changes are similar to those for the average which agree with a rightward shift of the future INT PDFs.

Again, the changes in the PDFs of HW properties, namely their central and extreme right measures, represent an aggravation of heat-related health impacts for the future. The apparently small changes in RF and INT should not be interpreted alone. They should be considered together with the increase in HW duration and, most importantly, with the number of HW days which strongly increases in the future climates.

Knowing that the key mechanism associated with HWs is the persistent presence of an anticyclonic pattern over a high-temperature region (Cassou et al., 2005) and that a link between the 'Atlantic Multidecadal Oscillation' and HWs was established (Della-Marta et al., 2007), it is reasonable to assume that a change in the typical location of high-pressure systems or other synoptic features associated with HWs over Europe may change.

Figure 6 shows an example of what we might expect to be a mid-term and long-term future HW. The figure

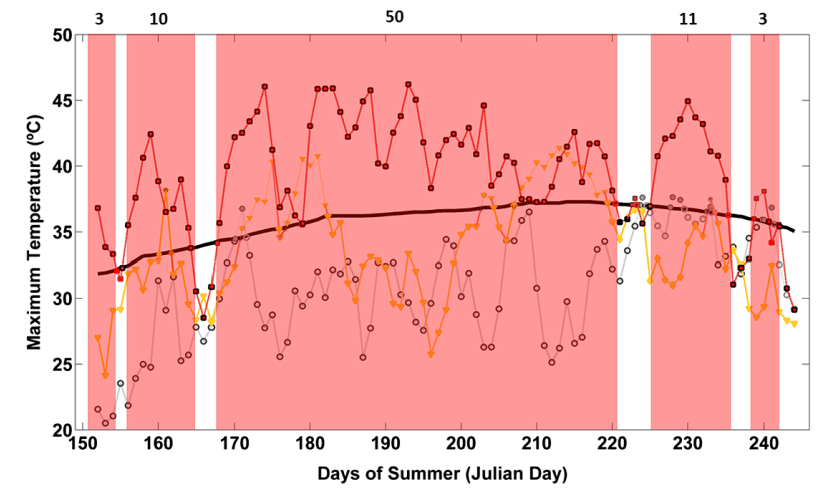

Figure 6. Time series of maximum temperature simulated for Jerez. The thick solid black line indicates the daily climatological 90th percentile (HW threshold) for the reference climate (1986-2005). The grey open dotted line represents a typical summer for the reference climate. The yellow line with triangles represents a typical summer for the mid-term climate (2046-2065) and the red line with squares represents a typical summer for the long-term climate (2081-2100). The pink shaded area shows HWs identified for this particular summer. The HW DUR of each HW appears at the top of the figure. [Colour figure can be viewed at wileyonlinelibrary.com].

shows a particular warm summer (similar to the summer of 2003) at a particular location in the recent-past (grey line), mid-term (green line) and long-term future (red line). The reference threshold (i.e. that for the recent-past climate simulated by the WRF-MPI) is shown by the thick black line. Black-circled dots represent HW days. The observed tendency is for an increase in the number of HW days even if the number of HWs does not increase. Also, the average intensity of HWs, as defined in this study, may not be higher for the future even if the number of HW days increases.

\subsection{Cold spells}

As was done for HW, CS numbers and characteristics comparison between future and present climates simulated by the WRF-MPI uses the threshold of the simulated present climate.

Figure 7 shows the PDFs of DUR, RF and INT for CSs in the three climate periods, in a similar way as for HWs in Figure 5. Table 4 shows the same properties of the PDFs for CSs at the 12 urban locations over the IP. For some locations, CSs do not occur in the long-term future (absence of PDF in Figure 7 and 0.000 values for Nwaves and '-' symbol in Table 4). In some cases, changes are not statistically significant (i.e. $H=0$ ). In general, there is a decrease in the number of CSs and CSs $N$ days for the future. The PDFs of DUR shift to the left (Figure 7) also confirmed by the decreases in the mean and extreme percentile changes (Table 4). These represent a decrease in duration of CSs. There are also changes of variance for some PDFs, particularly for DUR and RF. Changes in the PDFs of RF and INT are small, generally associated with a shift towards the left, particularly for INT (i.e. less intense CSs). However, these should be treated with caution since the number of CSs is very small. As expected, CSs health-related impacts may 

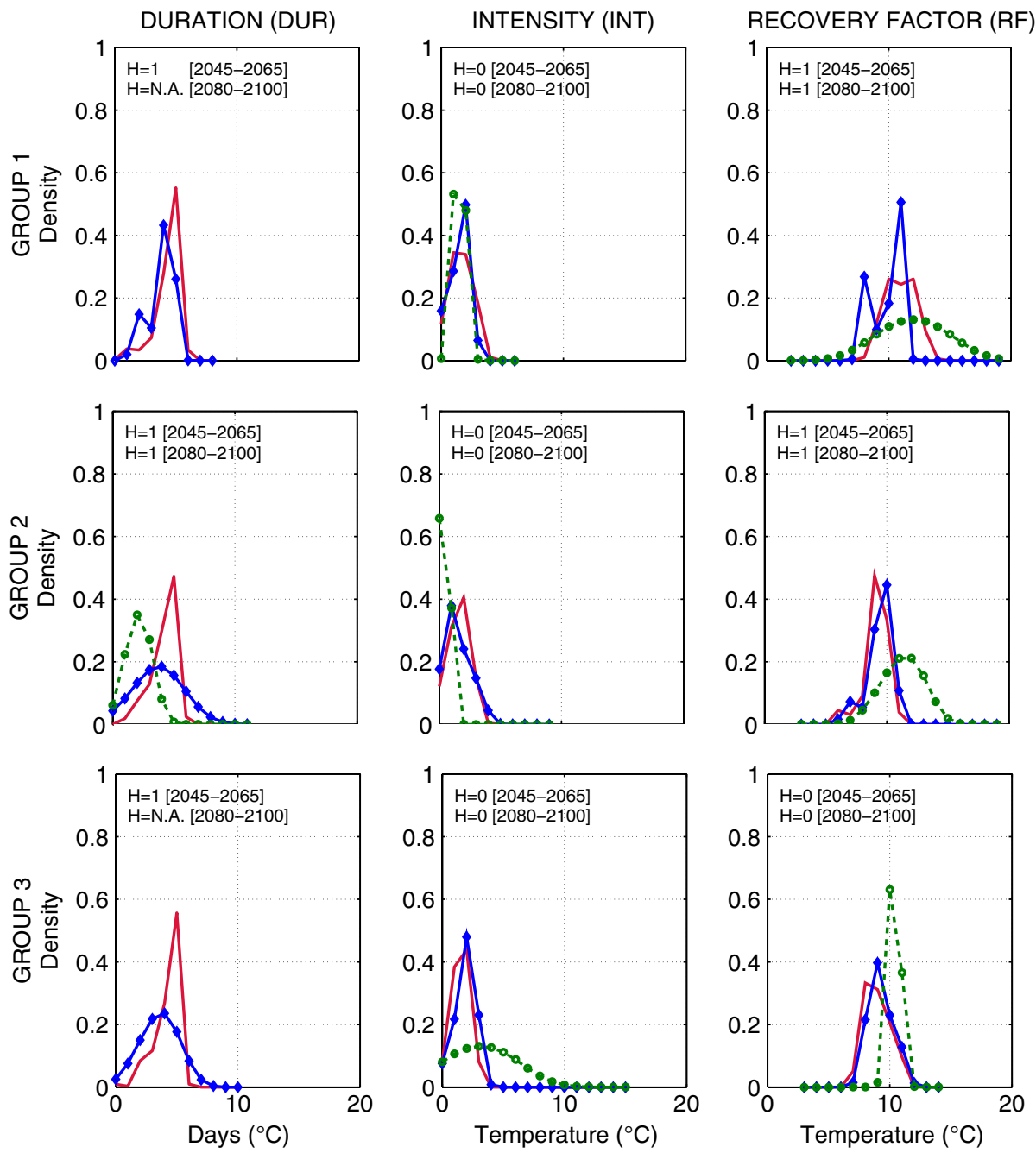

$-1986-2005-\rightarrow-2046-2065-\bullet-2081-2100$

Figure 7. The same as Figure 5 but for CSs. The case of no dotted green line means that no CSs were detectable in the mid-term future 2081-2100, and the Kolmogorov-Smirnov test appears with $\mathrm{NaN}$ as result. [Colour figure can be viewed at wileyonlinelibrary.com].

decrease in the future associated to warmer temperatures $\left(T_{\min }\right.$ and $\left.T_{\max }\right)$.

The absence of CSs is consistent with other results that point for a decrease of cold days towards the end of 20th century (Lhotka and Kysely, 2015). In the past and over the IP, the cold nights' index was estimated as a negative trend of $6^{\circ} \mathrm{C} / \mathrm{dec}$ ade (Zhang et al., 2011). For temperature extremes in general, most global regions show larger increases in minimum than maximum temperature (Perkins et al., 2012) which can explain the fewer CS. However, in a recent study Fonseca et al. (2015) found an increase in the number of warm days and warm nights, particularly for summer and a negative trends for cold nights and cold days in the summer. It was also reported an increase in cold days and cold nights during wintertime.

\section{Conclusion}

In this study, changes of HWs' and CSs' characteristics are evaluated for 12 locations over the IP that may occur in two future climate periods under the RCP 8.5 emission scenario. This is achieved by comparing the number of $\mathrm{HWs} / \mathrm{CSs}$, the number of HWs/CSs days, their duration, recovery factor and intensity between the two future periods, namely mid-term (2046-2065) and long-term (2081-2100), with the recent-past reference climate (1986-2005). The statistical differences of changes are also estimated. HWs/CSs are defined as a period of a minimum of three consecutive days with daily $T_{\max } / T_{\min }$ above/below a threshold define as the climatological 90th/10th percentile. The thresholds used for all periods are those defined for the reference climate since one of the objective is to generate information which could be used for future temperature health-related adaptation measures. For both future periods, the number of HWs and HW days are expected to increase in all locations. The first register increases between 2 and 4 fold relative to present day conditions. For the latter, changes are expected to reach between 4 and 40 times the simulated present climate values. Smallest changes will occur in 
Table 4. Statistics of the CSs properties', namely $N$ waves, $N$ days, mean, and 95th, percentile for DUR, RF and INT.

\begin{tabular}{|c|c|c|c|c|c|c|c|c|c|}
\hline \multirow[t]{2}{*}{ Location } & & \multicolumn{2}{|c|}{$N$ waves $N$ days } & \multicolumn{2}{|c|}{ Duration (days) } & \multicolumn{2}{|c|}{ Recovery Factor $\left({ }^{\circ} \mathrm{C}\right)$} & \multicolumn{2}{|c|}{ Intensity $\left({ }^{\circ} \mathrm{C}\right)$} \\
\hline & & & & Mean & p95 & Mean & p95 & Mean & p95 \\
\hline \multirow[t]{3}{*}{ Braganca } & $1986-2005$ & 1.29 & 5.38 & 4.19 & 8.00 & 7.89 & 10.63 & 1.44 & 2.64 \\
\hline & $2046-2065$ & 0.24 & 0.76 & 3.20 & 4.00 & 8.46 & 10.08 & 1.58 & 1.70 \\
\hline & $2081-2100$ & 0.00 & 0.00 & - & - & - & - & - & - \\
\hline \multirow[t]{3}{*}{ Beja } & $1986-2005$ & 1.00 & 4.24 & 4.24 & 7.00 & 12.18 & 14.41 & 1.67 & 3.33 \\
\hline & 2046-2065 & 0.19 & 0.67 & 3.50 & 4.00 & 12.60 & 13.72 & 1.37 & 1.90 \\
\hline & $2081-2100$ & 0.10 & 0.29 & 3.00 & 3.00 & 11.22 & 12.47 & 0.81 & 0.98 \\
\hline \multirow[t]{3}{*}{ Porto } & $1986-2005$ & 1.24 & 4.95 & 4.00 & 7.20 & 8.74 & 10.20 & 1.32 & 2.34 \\
\hline & $2046-2065$ & 0.33 & 1.38 & 4.14 & 9.00 & 8.37 & 9.33 & 1.06 & 1.53 \\
\hline & $2081-2100$ & 0.05 & 0.19 & 4.00 & 4.00 & 8.57 & 8.57 & 0.31 & 0.31 \\
\hline \multirow[t]{3}{*}{ Lisboa } & $1986-2005$ & 1.43 & 5.81 & 4.07 & 8.00 & 12.32 & 14.89 & 1.37 & 2.33 \\
\hline & $2046-2065$ & 0.19 & 0.62 & 3.25 & 4.00 & 12.60 & 13.66 & 1.08 & 1.73 \\
\hline & $2081-2100$ & 0.00 & 0.00 & - & - & - & - & - & - \\
\hline \multirow[t]{3}{*}{ Barcelona } & $1986-2005$ & 1.19 & 5.43 & 4.56 & 8.00 & 8.04 & 9.17 & 1.46 & 2.91 \\
\hline & $2046-2065$ & 0.43 & 1.57 & 3.67 & 6.00 & 8.01 & 9.46 & 1.24 & 1.63 \\
\hline & $2081-2100$ & 0.10 & 0.33 & 3.50 & 4.00 & 9.62 & 10.62 & 1.05 & 1.44 \\
\hline \multirow[t]{3}{*}{ Madrid } & $1986-2005$ & 1.19 & 4.57 & 3.84 & 7.25 & 6.16 & 8.25 & 1.10 & 2.31 \\
\hline & $2046-2065$ & 0.19 & 0.62 & 3.25 & 4.00 & 7.95 & 8.99 & 1.79 & 3.56 \\
\hline & $2081-2100$ & 0.00 & 0.00 & - & - & - & - & - & - \\
\hline \multirow[t]{3}{*}{ Corunha } & $1986-2005$ & 1.10 & 4.48 & 4.09 & 7.40 & 6.33 & 7.95 & 1.61 & 3.05 \\
\hline & $2046-2065$ & 0.38 & 1.52 & 4.00 & 6.00 & 6.11 & 7.50 & 1.10 & 2.40 \\
\hline & $2081-2100$ & 0.05 & 0.14 & 3.00 & 3.00 & 5.34 & 5.34 & 0.93 & 0.93 \\
\hline \multirow[t]{3}{*}{ Cárceres } & $1986-2005$ & 1.24 & 5.62 & 4.54 & 8.60 & 10.98 & 13.38 & 1.90 & 4.19 \\
\hline & $2046-2065$ & 0.24 & 0.95 & 4.00 & 5.00 & 10.28 & 12.29 & 1.49 & 2.30 \\
\hline & $2081-2100$ & 0.05 & 0.14 & 3.00 & 3.00 & 12.12 & 12.12 & 1.06 & 1.06 \\
\hline \multirow[t]{3}{*}{ Sevilha } & $1986-2005$ & 1.10 & 4.90 & 4.48 & 7.35 & 12.23 & 14.93 & 1.30 & 3.04 \\
\hline & $2046-2065$ & 0.14 & 0.57 & 4.00 & 4.00 & 11.83 & 13.13 & 0.77 & 1.21 \\
\hline & $2081-2100$ & 0.00 & 0.00 & - & - & - & - & - & - \\
\hline \multirow[t]{3}{*}{ Gijón } & $1986-2005$ & 1.33 & 5.10 & 3.82 & 6.00 & 7.43 & 8.74 & 1.39 & 2.76 \\
\hline & $2046-2065$ & 0.19 & 0.67 & 3.50 & 5.00 & 7.19 & 7.72 & 1.37 & 1.68 \\
\hline & $2081-2100$ & 0.05 & 0.19 & 4.00 & 4.00 & 8.04 & 8.04 & 1.17 & 1.17 \\
\hline \multirow[t]{3}{*}{ Valencia } & $1986-2005$ & 1.14 & 5.00 & 4.38 & 7.00 & 7.04 & 8.93 & 1.44 & 2.54 \\
\hline & $2046-2065$ & 0.24 & 0.90 & 3.80 & 5.00 & 7.49 & 8.09 & 1.19 & 1.74 \\
\hline & $2081-2100$ & 0.00 & 0.00 & - & - & - & - & - & - \\
\hline \multirow[t]{3}{*}{ Jerez } & $1986-2005$ & 1.10 & 4.62 & 4.22 & 6.70 & 11.00 & 12.92 & 1.48 & 3.27 \\
\hline & $2046-2065$ & 0.19 & 0.71 & 3.75 & 5.00 & 11.34 & 11.73 & 1.38 & 2.54 \\
\hline & $2081-2100$ & 0.00 & 0.00 & - & - & - & - & - & - \\
\hline
\end{tabular}

The mean $N$ waves and $N$ days were tested using the $T$-test at $\alpha=0.05$ under the null hypothesis that the samples come from independent random samples with equal means, and equal, but unknown, variances. If the value is highlighted (bold) the test rejects the null hypothesis at the 5\% significance level. Ndays and DUR are per CS and Nwaves per summer/winter.

the north (Gijón and Corunha) and highest changes in Barcelona where a great part of summer registering, on average, HW days. Average HW duration is expected to increase significantly at all locations. Results for the recovery factor and intensity point towards a slight, but statistically significant, increases at most locations and for both future periods. These changes should be considered together with the extreme increase in HW number and days. The above mentioned changes in HW properties are expected to increase across the whole duration/recovery factor/intensity range of HWs. As expected, CSs are estimated to decrease in number, duration and intensity associated with increases in night (i.e. $T_{\min }$ ) and day (i.e. $T_{\max }$ ) temperatures. Changes in CSs represent less cold-related health impacts but the magnitude and statistical significance of these changes as less than those of HWs. This work complements the existing climate change studies for IP and throws light in the HW and
CS characteristics for the future. The results of this study represent added-value to the implementation of adaptation measures associated to heat-related health risks for the future in the IP, particularly for its cities.

\section{Acknowledgements}

The authors thank for the financial support to CESAM (UID/AMB/50017), to FCT/MEC through national funds, and the co-funding by the FEDER, within the PT2020 Partnership Agreement and Compete 2020.

The authors also wish to thank the financial support of the DOUROZONE project (PTDC/AAG-MAA/ 3335/2014; POCI-01-0145-FEDER-016778) through the Project 3599 - Promoting the scientific production and the technological development, and thematic networks (3599-PPCDT) and through FEDER 


\section{References}

AEMET-IM, Agencia Estatal de Meteorología España and Instituto de Meteorologia de Portugal, (2011), Iberian Climate Atlas Air Temperature and Precipitation (1971-2000), Agencia Estatal de Meteorología, Ministerio de Medio Ambiente y Medio Rura y Marino (Ed), http://www.aemet.es/documentos/es/conocermas/ publicaciones/Atlas-climatologico/Atlas.pdf (accessed 31 July 2016)

Barata M, Ligeti E, De Simone G, Dickinson T, Jack D, Penney J, Rahman M, Zimmerman R. 2011. Climate change and human health in cities. In Climate Change and Cities, Rosenzweig C, Soleck WD, Hammer SA, Mehrotra S (eds). Cambridge University Press: Cambridge, UK, 179-213.

Barnett A, Hajat S, Gasparrini A, Rocklöv J. 2012. Cold and heat waves in the united states. Environ. Res. 112: 218-224. https://doi.org/10 .1016/j.envres.2011.12.010.

Barriopedro D, Fischer EM, Luterbacher J, Trigo RM, García-Herrera R. 2011. The hot summer of 2010: redrawing the temperature record map of europe. Science 332(6026): 220-224. https://doi.org/10.1126/ science. 1201224

Bowman A, Azzalini A. 1997. Applied Smoothing Techniques for Data Analysis with S-Plus illustrations. Oxford University Press: New York, NY.

Brunet M, Jones PD, Sigró J, Saladié O, Aguilar E, Moberg A, Della-Marta PM, Lister D, Walther A, López D. 2007. Temporal and spatial temperature variability and change over Spain during 1850-2005. J. Geophys. Res. Atmos. 112: D12117. https://doi.org/10 1029/2006JD008249.

Carvalho MJ, Melo-Gonçalves P, Teixeira JC, Rocha A. 2016. Regionalization of europe based on a k-means cluster analysis of the climate change of temperatures and precipitation. Phys. Chem. Earth 94 22-28. https://doi.org/10.1016/j.pce.2016.05.001.

Cassou C, Terray L, Phillips AS. 2005. Tropical Atlantic influence on european heat waves. J. Climate 18(15): 2805-2811. https://doi.org/ 10.1175/JCLI3506.1

Chen F, Kusaka H, Tewari M, Bao J, Hirakuchi H. 2004. Utilizing the coupled wrf/lsm/urban modeling system with detailed urban classification to simulate the urban heat island phenomena over the greater Houston area. In Fifth Symposium on the Urban Environment, pp. $9-11$

Ciscar JC, Feyen L, Soria A, Lavalle C, Raes F, Perry M, Nemry F, Demirel H, Rozsai M, Dosio A, Donatelli M, Srivastava A, Fumagalli D, Niemeyer S, Shrestha S, Ciaian P, Himics M, Van Doorslaer B Barrios S, Ibáñez N, Forzieri G, Rojas R, Bianchi A, Dowling P, Camia A, Libertà G, San Miguel J, de Rigo D, Caudullo G, Barredo JI, Paci D, Pycroft J, Saveyn B, Van Regemorter D, Revesz T, Vandyck T, Vrontisi Z, Baranzelli C, Vandecasteele I, Batista e Silva F, Ibarreta D (2014). Climate Impacts in Europe. The JRC PESETA II Project. JRC Scientific and Policy Reports, EUR 26586EN. https://doi.org/10 .2791/7409

Cutter S, Osman-Elasha B, Campbell J, Cheong S-M, McCormick S, Pulwarty R, Supratid S, Ziervogel G. 2012. Managing the risks from climate extremes at the local level. In Managing the Risks of Extreme Events and Disasters to Advance Climate Change Adaptation, Field CB, Barros V, Stocker TF, Qin D, Dokken DJ, Ebi KL, Mastrandrea MD, Mach KJ, Plattner G-K, Allen SK, Tignor M, Midgley PM (eds). Cambridge University Press: Cambridge and New York, NY, 291-338.

Della-Marta PM, Haylock MR, Luterbacher J, Wanner H. 2007. Doubled length of Western European summer heat waves since 1880. J. Geophys. Res. Atmos. 112: D15103. https://doi.org/10.1029/ 2007JD008510.

Domínguez M, Romera R, Sánchez E, Fita L, Fernández J, Jiménez-Guerrero P, Montávez JP, Cabos WD, Liguori G, Gaertner MÁ. 2013. Present-climate precipitation and temperature extremes over Spain from a set of high resolution RCMs. Climate Res. 58(2): 149-164.

Dudhia J. 1989. Numerical study of convection observed during the winter monsoon experiment using a mesoscale two-dimensional model. J. Atmos. Sci. 46(20): 3077-3107. https://doi.org/10.1175/15200469(1989)046<3077:NSOCOD>2.0.CO;2.

Fernández-González S, Pereira SC, Castro A, Rocha A, Fraile R. 2014. Connection between autumn sea surface temperature and winter precipitation in the Iberian peninsula. Global Planet. Change 121: 9-18.

Fonseca D, Carvalho M, Marta-Almeida M, Melo-Gonçalves P, Rocha A. 2015. Recent trends of extreme temperature indices for the Iberian peninsula. Phys. Chem. Earth 94: 66-76. https://doi.org/10.1016/j .pce.2015.12.005.
Forzieri G, Feyen L, Russo S, Vousdoukas M, Alfieri L, Stephen O, Migliavacca M, Bianchi A, Rojas R, Cid A. 2016. Multi-hazard assessment in Europe under climate change. Clim. Change 137: 105-119. https://doi.org/10.1007/s10584-016-1661-x

Frich P, Alexander L, Della-Marta P, Gleason B, Haylock M, Klein Tank A, Peterson T. 2002. Observed coherent changes in climatic extremes during the second half of the twentieth century. Climate Res. 19(3): 193-212. https://doi.org/10.3354/cr019193.

Grell GA, Freitas SR. 2013. A scale and aerosol aware stochastic convective parameterization for weather and air quality modeling. Atmos. Chem. Phys. Discuss. 13(9): 23845-23893. https://doi.org/10 .5194/acpd-13-23845-2013.

Hansen A, Bi P, Nitschke M, Ryan P, Pisaniello D, Tucker G. 2008. The effect of heatwaves on mental health in a temperate Australian city. Epidemiology 19(6): S85. https://doi.org/10.1097/01.ede.0000339795 .05175.c2.

Haylock MR, Hofstra N, Klein Tank AMG, Klok EJ, Jones PD, New M. 2008. A European daily high-resolution gridded data set of surface temperature and precipitation for 1950-2006. J. Geophys. Res. 113: D20119. https://doi.org/10.1029/2008JD010201.

Herrera S, Fernández J, Gutiérrez JM. 2016. Update of the Spain02 Gridded Observational Dataset for Euro-CORDEX evaluation: assessing the effect of the interpolation methodology. Int. J. Climatol. 36: 900-908. https://doi.org/10.1002/joc.4391.

Hong S-Y, Lim J-OJ. 2006. The WRF single-moment 6-class microphysics scheme (wsm6). J. Korean Meteorol. Soc 42(2): 129-151.

Hong S-Y, Noh Y, Dudhia J. 2006. A new vertical diffusion package with an explicit treatment of entrainment processes. Mon. Weather Rev. 134(9): 2318-2341. https://doi.org/10.1175/MWR3199.1.

Karl TR, Knight RW. 1997. The 1995 Chicago heat wave: how likely is a recurrence? Bull. Am. Meteorol. Soc. 78(6): 1107-1119.

Katragkou E, Garcia-Diez M, Vautard R, Sobolowski S, Zanis P, Alexandri G, Cardoso RM, Colette A, Fernandez J, Gobiet A, Goergen K, Karacostas T, Knist S, Mayer S, Soares PMM, Pytharoulis I, Tegoulias I, Tsikerdekis A, Jacob D. 2015. Regional climate hindcast simulations within EURO-CORDEX: evaluation of a WRF multi-physics ensemble. Geosci. Model Dev. 8: 603-618. https://doi.org/10.5194/gmd-8603-2015.

Kysely J. 2010. Recent severe heat waves in central europe: how to view them in a long-term prospect? Int. J. Climatol. 30(1): 89-109. https:// doi.org/10.1002/joc. 1874 .

Lau NC, Nath MJ. 2014. Model simulation and projection of European heat waves in present-day and future climates. J. Clim. 27(10): 3713-3730.

Lhotka O, Kysely J. 2015. Characterizing joint effects of spatial extent, temperature magnitude and duration of heat waves and cold spells over central europe. Int. J. Climatol. 35(7): 1232-1244. https://doi.org/10 .1002/joc.4050.

Lubchenco J, Karl TR. 2012. Extreme weather events. Phys. Today 65(3): 31. https://doi.org/10.1063/PT.3.1475.

Marta-Almeida M, Teixeira JC, Carvalho MJ, Gonçalves P, Rocha AM. 2016. High resolution WRF climatic simulations for the Iberian Peninsula: model validation. Phys. Chem. Earth 94: 94-105. https:// doi.org/10.1016/j.pce.2016.03.010.

Massey JF. 1956. The Kolmogorov-Smimov test for goodness of fit. $J$. Am. Stat. Assoc. 51(273): 111-121. https://doi.org/10.1080/01621459 1951.10500769.

Mlawer E, Clough S. 1997. On the extension of rapid radiative transfer model to the shortwave region. In Proceedings of the 6th Atmospheric Radiation Measurement (ARM) Science Team Meeting, US Department of Energy, CONF-9603149.

Moss R, Babiker M, Brinkman S, Calvo E, Carter T, Edmonds J, Elgizouli I, Emori S, Erda L, Hibbard K, Jones R, Kainuma M, Kelleher J, Lamarque JF, Manning M, Matthews B, Meehl J, Meyer L, Mitchell J, Nakicenovic N, O’Neill B, Pichs R, Riahi K, Rose S, Runci P, Stouffer R, van Vuuren D, Weyant J, Wilbanks T, van Ypersele JP, Zurek M. 2008. Towards New Scenarios for Analysis of Emissions, Climate Change, Impacts, and Response Strategies. Technical Summary. Intergovernmental Panel on Climate Change, Geneva. page 25 pp.

Nogueira PJ, Falcão JM, Contreias MT, Paixão E, Batista I. 2005. Mortality in Portugal associated with the heat wave of august 2003. Euro Suerveill. 10(7): 150-152.

Ouzeau G, Soubeyroux J-M, Schneider M, Vautard R, Planton S. 2016. Heat waves analysis over France in present and future climate: application of a new method on the EURO-CORDEX ensemble. Clim. Services 4: 1-12. 


\section{S. C. PEREIRA et al.}

Pereira S, Carvalho A, Ferreira J, Nunes J, Keizer J, Rocha A. 2013. Simulation of a persistent medium-term precipitation event over the western Iberian peninsula. Hydrol. Earth Syst. Sci. 17(10): 3741-3758. https://doi.org/10.5194/hess-17-3741-2013.

Perkins S. 2015. A review on the scientific understanding of heat waves: their measurement, driving mechanisms, and changes at the global scale. Atmos. Res. 164-165(2015): 242-267.

Perkins SE, Alexander LV, Nairn JR. 2012. Increasing frequency, intensity and duration of observed global heatwaves and warm spells. Geophys. Res. Lett. 39(20): L20714. https://doi.org/10.1029/ 2012GL053361.

Peterson TC, Stott PA, Herring S. 2012. Explaining extreme events of 2011 from a climate perspective. Bull. Am. Meteorol. Soc. 93(7): 1041-1067. https://doi.org/10.1175/BAMS-D-12-00021.1.

Peterson TC, Heim RR Jr, Hirsch R, Kaiser DP, Brooks H, Diffenbaugh NS, Dole RM, Giovannettone JP, Guirguis K, Karl TR et al. 2013. Monitoring and understanding changes in heat waves, cold waves, floods, and droughts in the united states: state of knowledge. Bull. Am. Meteorol. Soc. 94(6): 821-834. https://doi.org/10.1175/BAMSD-12-00066.1.

Robinson PJ. 2001. On the definition of a heat wave. J. Appl. Meteorol. 40(4): 762-775. https://doi.org/10.1175/1520-0450(2001)040<0762: OTDOAH > 2.0.CO;2.

Russo S, Dosio A, Graversen RG, Sillmann J, Carrao H, Dunbar MB, Singleton A, Montagna P, Barbola P, Vogt JV. 2014. Magnitude of extreme heat waves in present climate and their projection in a warming world. J. Geophys. Res. Atmos. 119: 500-512.

Schär C, Vidale PL, Lüthi D, Frei C, Häberli C, Liniger MA, Appenzeller C. 2004. The role of increasing temperature variability in European summer heatwaves. Nature 427(6972): 332-336.

Schoetter R, Cattiaux J, Douville H. 2015. Changes of western European heat wave characteristics projected by the CMIP5 ensemble. Climate Dyn. 45(5-6): 1601. https://doi.org/10.1007/s00382-014-2434-8.
Simón F, Lopez-Abvente G, Ballester E, Martínez F. 2005. Mortality in Spain during the heat wave of summer 2003. Euro Suerveill. 10(7): $156-160$.

Skamarock WC, Klemp JB, Dudhia J, Gill DO, Barker DM, Wang W, Powers JG. 2005. A description of the advanced research WRF version 2 (No. NCAR/TN-468+ STR). National Center For Atmospheric Research Boulder Co Mesoscale and Microscale Meteorology Div.

Tomczyk AM, Bednorz E. 2016. Heat waves in Central Europe and their circulation conditions. Int. J. Climatol. 36: 770-782. https://doi.org/ 10.1002/joc. 4381 .

Tong S, Wang XY, Barnett AG. 2010. Assessment of heat-related health impacts in Brisbane, Australia: comparison of different heatwave definitions. PLoS One 5(8): e12155. https://doi.org/10.1371/journal pone.0012155.

Vautard R, Gobiet A, Jacob D, Belda M, Colette A, Déqué M, Halenka T. 2013. The simulation of European heat waves from an ensemble of regional climate models within the EURO-CORDEX project. Climate Dyn. 41(9-10): 2555-2575.

WMO. 2011. A snapshot of extreme events over the past decade. The World Meteorological Organization: Geneva, Switzerland. http:// www.wmo.int/pages/prog/wcp/cop16/documents/extremes.pdf (last accessed 2016-07-31).

Zhang D, Anthes RA. 1982. A high-resolution model of the planetary boundary layer-sensitivity tests and comparisons with sesame-79 data. J. Appl. Meteorol. 21(11): 1594-1609. https://doi.org/10. 1175/1520-0450(1982)021<1594:AHRMOT>2.0.CO;2.

Zhang X, Alexander L, Hegerl GC, Jones P, Klein Tank AK, Peterson TC, Trewin B, Zwiers FW. 2011. Indices for monitoring changes in extremes based on daily temperature and precipitation data. WIREs Clim. Change 2: 851-870. https://doi.org/doi:10.1002/wcc.147.

Zuo J, Pullen S, Palmer J, Bennetts H, Chileshe N, Ma T. 2015. Impacts of heat waves and corresponding measures: a review. J. Clean. Prod. 92: 1 -12. https://doi.org/10.1016/j.jclepro.2014.12.078. 